\title{
Synthesis and Release of Hageman Factor (Factor XII) by the Isolated Perfused Rat Liver
}

\author{
Hidehiko Saito, Stewart M. Hamilton, Anthony S. Tavill, \\ Lawrence T. Goodnough, Loizos Louis, and Alan Angell, Departments \\ of Medicine, Case Western Reserve University School of Medicine at \\ University Hospitals of Cleveland and Cleveland Metropolitan General \\ Hospital, Cleveland, Ohio 44106; Saga Medical School, Saga, Japan
}

A в S T R A C T The site of synthesis of Hageman factor (HF, Factor XII) has not been previously demonstrated with certainty. We have studied the production and release of $\mathrm{HF}$ in the isolated perfused rat liver and have compared rates of synthesis in this system with absolute rates of degradation measured in vivo. Rat livers, perfused for $5 \mathrm{~h}$ with a recycling fluid consisting of a perfluorochemical emulsion (Fluosol 43), were used to demonstrate a cumulative increase of $\mathrm{HF}$ in the perfusate as measured by a specific and sensitive radioimmunoassay. The rate of increase in the perfusate pool of $\mathrm{HF}$ during the final $4 \mathrm{~h}$ of perfusion yielded a mean synthetic rate of $3.5 \mu \mathrm{g} / \mathrm{h}$ per $100 \mathrm{~g}$ body wt, which was $\sim 0.2 \%$ of the synthetic rate of albumin in the same system. The cumulative appearance of albumin and transferrin was linear after $1 \mathrm{~h}$ and calculated rates of synthesis were $2,012 \mu \mathrm{g} / \mathrm{h}$ per $100 \mathrm{~g}$ and $263 \mu \mathrm{g} / \mathrm{h}$ per $100 \mathrm{~g}$ body wt, respectively. De novo synthesis of $\mathrm{HF}$ was confirmed by demonstrating incorporation of $\left[{ }^{14} \mathrm{C}\right]$ lysine into specific immunoprecipitates of $\mathrm{HF}$, and by the observations that both specific incorporation of labeled amino acid and net release of immunoassayable $\mathrm{HF}$ were inhibited by the administration of cycloheximide. Finally, it was evident that the rates of synthesis observed in the isolated perfused liver agreed closely with absolute rates of degradation of $\mathrm{HF}$ measured in vivo with ${ }^{125} \mathrm{I}$-rat

A preliminary report of this study was presented at the Central Society for Clinical Research, Chicago, 7 November 1980 and appeared in abstract form in 1980. Clin. Res. 28:770a. (Abstr.)

Dr. Lawrence T. Goodnough is the recipient of the American Heart Association Clinician Scientist Award 81-412. Address all correspondence to Dr. H. Saito, Saga Medical School, Nabeshima, Saga 840, Japan.

Received for publication 31 January 1983 and in revised form 27 May 1983.
HF $(4.0 \mu \mathrm{g} / \mathrm{h}$ per $100 \mathrm{~g})$. From these data we conclude that the liver is the principal site of synthesis of HF.

\section{INTRODUCTION}

Hageman factor $\left(\mathrm{HF}^{1}\right.$, Factor XII) is a plasma protein with an approximate molecular weight of 80,000 present in the blood of most mammals. Under certain conditions $\mathrm{HF}$ triggers several contact-activated plasma reactions such as blood coagulation, kinin generation, and fibrinolysis (2). The normal concentration of $\mathrm{HF}$ in human plasma is $\sim 3-4 \mathrm{mg} / \mathrm{dl}(3)$ and the plasma half-life of $\mathrm{HF}$ in man has been reported to be $\sim 50$ $60 \mathrm{~h}$ following the infusion of normal plasma into individuals with hereditary HF deficiency (4). The site of synthesis of HF is not known with certainty, although earlier observations have indirectly suggested that the liver may be a site of production and secretion.

In this study we have purified HF from rat plasma and raised a monospecific antiserum against rat $\mathrm{HF}$ in rabbits, which has enabled us to develop a specific and sensitive radioimmunoassay for rat HF. By means of this assay we have shown that isolated perfused rat liver produces and releases $\mathrm{HF}$ into the circulation. $D e$ novo synthesis of $\mathrm{HF}$ was confirmed by demonstrating the incorporation of $\left[{ }^{14} \mathrm{C}\right]$ lysine into specific immunoprecipitates of $\mathrm{HF}$ derived from the circulating perfusate, and by inhibition of synthesis by cycloheximide. Furthermore, we have measured the half-disappearance time of radioiodine-labeled HF in intact rats and have estimated its absolute catabolic rate, which agrees closely with the rates of synthesis determined in vitro in the isolated perfused liver.

\footnotetext{
${ }^{1}$ Abbreviations used in this paper: HF, Hageman factor; SDS-PAGE, sodium dodecyl sulfate-polyacrylamide gel electrophoresis.
} 


\section{METHODS}

Procoagulant activities measurement. The procoagulant activities of HF (Factor XII), plasma thromboplastin antecedent (Factor XI), prekallikrein, high-molecular-weight kininogen, Christmas factor (Factor IX), and antihemophilic factor (AHF, Factor VIII) were measured by the kaolin-activated partial thromboplastin time using congenital-deficient plasma as substrate $(5,6)$.

Isolation and characterization of rat HF. Rat HF was isolated from $700 \mathrm{ml}$ of pooled plasma from Sprague-Dawley rats (Pel Freez Biologicals, Rogers, AR) by a method described for human HF (7). The purified preparation had a specific activity of 22 units/mg protein $(1$ unit being defined as that amount present in $1.0 \mathrm{ml}$ of pooled rat plasma) and it showed a single stained protein band on analytical polyacrylamide disc gel electrophoresis (8). This band contained clot-promoting activity for human HF-deficient plasma, as tested by assaying eluates from 1-mm segments of replicate gels (Fig. 1). Upon sodium dodecyl sulfate polyacrylamide gel electrophoresis (SDS-PAGE) (9) rat HF yielded a single major protein band in the presence and absence of a reducing agent, 2-mercaptoethanol (Fig. 2). The same protein band also yielded a positive periodic acid-Schiff stain (10). The apparent molecular weight of rat $\mathrm{HF}$ was $\sim 80,000$ and isoelectric focusing (11) revealed a $\mathrm{pI}$ of 5.1-5.5. These results suggest that rat $\mathrm{HF}$ is a single-chain glycoprotein with a molecular weight of $\sim 80,000$, similar to human and bovine HF $(12,13)$. The amino acid composition of rat $\mathrm{HF}$ is also very similar to that of human HF (Table I).

Anti-rat HF serum. Anti-rat HF serum was raised in New Zealand albino rabbits by injections of purified rat HF. Upon Ouchterlony immunodiffusion, this antiserum showed a single precipitin line of complete identity with purified rat $\mathrm{HF}$ and rat plasma (Fig. 3). Furthermore, the antiserum selectively blocked HF clot-promoting activity without significant inhibition of activities of other clotting factors (Table II). These results indicate that this antiserum contains antibodies that are monospecific immunologically and functionally. A crude immunoglobulin fraction of the antiserum was isolated as described earlier (14). A similar fraction of normal rabbit serum was used as control in all experiments involving immunoprecipitation techniques.

Development of a radioimmunoassay (RIA) for rat $H F$. By the use of purified rat HF and its antiserum, a specific and sensitive RIA was developed as previously described for human HF (3). When pooled rat plasma or purified rat HF

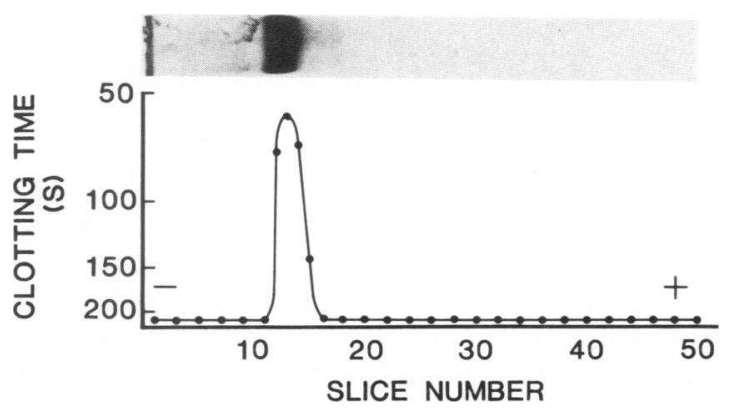

FIGURE 1 Analysis of rat HF on analytical polyacrylamide gel. The gel above was stained with $0.05 \%$ Coomassie Blue, while a replicate gel was sliced, eluted, and assayed for $\mathrm{HF}$ clot-promoting activity.

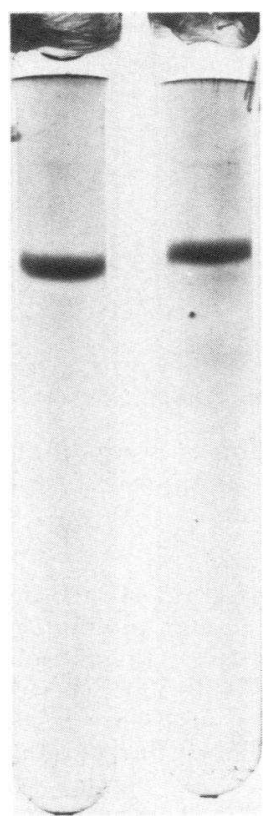

Figure 2 SDS-PAGE of rat HF (A) before and $(B)$ after reduction with 2-mercaptoethanol. Anode is at the bottom.

was tested in this assay, similar displacement curves were obtained (Fig. 4). The assay is sensitive to $0.05 \mu \mathrm{g} \mathrm{HF} / \mathrm{ml}$ or $0.125 \%$ of the concentration of $\mathrm{HF}$ present in normal pooled rat plasma. The concentration of $\mathrm{HF}$ present in rat plasma was estimated to be $\sim 40 \mu \mathrm{g} / \mathrm{ml}$ compared to a stan-

TABLE I

Amino Acid Analysis of Rat $\mathrm{HF}$

\begin{tabular}{lrr}
\hline \multicolumn{1}{c}{ Amino acid } & Rat HF & Human HFt \\
\hline & \multicolumn{2}{c}{$\%$} \\
Cysteine & 3.9 & \\
Aspartic acid & 9.0 & 4.2 \\
Threonine & 5.1 & 6.3 \\
Serine & 5.9 & 5.8 \\
Glutamic acid & 11.0 & 8.5 \\
Proline & 6.9 & 11.3 \\
Glycine & 9.7 & 8.9 \\
Alanine & 7.0 & 10.5 \\
Methionine & 0.8 & 9.2 \\
Valine & 6.4 & 0.1 \\
Isoleucine & 2.4 & 5.4 \\
Leucine & 10.3 & 1.4 \\
Tyrosine & 3.2 & 7.6 \\
Phenylalanine & 3.5 & 2.8 \\
Lysine & 4.2 & 2.9 \\
Histidine & 4.8 & 4.2 \\
Arginine & 6.0 & 4.5 \\
\hline
\end{tabular}

The techniques used did not permit estimation of tryptophan.

- Data represent mean of two separate batches of rat HF.

† Obtained from reference 7 . 


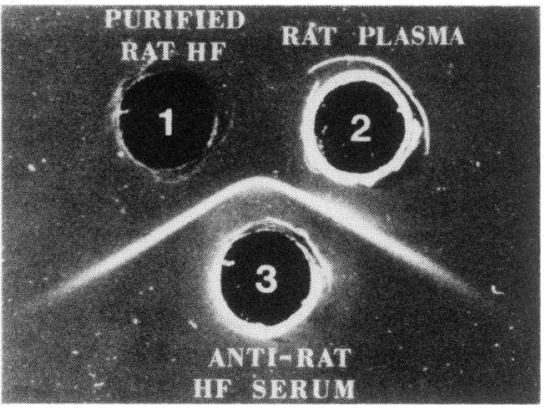

Figure 3 Immunodiffusion study of anti-rat HF serum (3) against rat plasma (2) and purified rat HF (1).

dard curve using puritied rat HF. This titer is very close to that found in normal human plasma (3).

Liver perfusion studies. Livers isolated from fed male Sprague-Dawley rats (400-500 g body wt) were perfused through the portal vein with recycling perfusate $(\sim 80 \mathrm{ml})$ of a heparinized (1,000 U) fluorocarbon emulsion (Fluosol 43; Green Cross Corp., Osaka, Japan), which is free of plasma proteins and blood cells. The perfluorocarbon components (perfluorotributylamine and pluronic F-68) were dialyzed overnight against deionized water, centrifuged at $2,700 \mathrm{~g}$ to remove nonemulsifed material, filtered through Whatman No. 1 filter paper (Whatman Chemical Separation, Inc., Clifton, $\mathrm{NJ}$ ) and mixed with the aqueous annex solution to give a final concentration of the following constituents (in grams per deciliter); perfluorotributylamine (20.0); pluronic F-68 (2.56); $\mathrm{NaCl}(0.6) ; \mathrm{KCl}(0.034) ; \mathrm{CaCl}_{2}(0.028)$; $\mathrm{MgCl}_{2}(0.02) ; \mathrm{NaHCO}_{3}(0.21)$; glucose (0.18); hydroxyethyl starch (3.0). The perfusate was maintained in gaseous equilibrium at $37^{\circ} \mathrm{C}$ with $95 \% \mathrm{O}_{2} / 5 \% \mathrm{CO}_{2}$ by means of a thinwalled silastic tubing membrane oxygenator $(25 \mathrm{ft}$ of coiled tubing, caliber 0.058-in. i.d., 0.077-in. o.d., Dow Corning

TABLE II

Functional Specificity of Anti-Rat HF Serum

\begin{tabular}{lcc}
\hline & \multicolumn{2}{c}{ Activities } \\
\cline { 2 - 3 } \multicolumn{1}{c}{ Clotting factor } & $\begin{array}{c}\text { Normal plasma } \\
+ \text { anti-HF serum }\end{array}$ & $\begin{array}{c}\text { Normal plasma } \\
+ \text { normal rabbit serum }\end{array}$ \\
\hline & & $\%$ \\
HF & $<1$ & 100 \\
Factor XI & 100 & 100 \\
Prekallikrein & 95 & 100 \\
High-molecular-weight & & \\
$\quad$ kininogen & 95 & 100 \\
Christmas factor & 94 & 100 \\
Factor VIII & 90 & 100 \\
\hline
\end{tabular}

- Adsorbed with $\mathrm{Ca}_{3}\left(\mathrm{PO}_{4}\right)_{2}$ and kaolin, and heated at $60^{\circ} \mathrm{C}$ for 1 h.

A 1:1 mixture (vol/vol) of normal pooled rat plasma and either rabbit anti-HF serum or normal rabbit serum was incubated at $37^{\circ} \mathrm{C}$ for $60 \mathrm{~min}$, and was then tested for various clotting factor activities after appropriate dilutions.
Corp., Midland, MI). Portal vein inflow $\mathrm{PO}_{2}$ of $>350 \mathrm{mmHg}$ was maintained by this method at hepatic perfusate flow rates of $15-20 \mathrm{ml} / \mathrm{min}$ and portal vein pressures of $15 \mathrm{~cm}$ of $\mathrm{H}_{2} \mathrm{O}$. Before the liver was placed in the perfusion circuit it was flushed with $20 \mathrm{ml}$ of oxygenated fluorocarbon to wash out residual blood. Measured additions to the perfusate consisted of sodium taurocholate $(18.6 \mathrm{mM}, 0.28 \mu \mathrm{mol} / \mathrm{min})$ to stimulate bile flow, and $\mathrm{NaHCO}_{3}(1.2 \mathrm{M})$ to adjust the monitored $\mathrm{pH}$ to 7.4 at hourly intervals. In some experiments, all glass surfaces in the perfusion system were washed with $100 \mu \mathrm{g} / \mathrm{ml}$ of hexadimethrine bromide (Polybrene, Aldrich Chemical Co. Inc., Milwaukee, WI) and rinsed with deionized water before use.

Samples of perfusate $(3-5 \mathrm{ml})$ were withdrawn at hourly intervals and centrifuged at $12,000 \mathrm{~g}$ for $30 \mathrm{~min}$ to sediment the suspended perfluorochemicals. The clear supernatant, to which aprotinin (Sigma Chemical Co., St. Louis, MO) was added (10 units $/ \mathrm{ml}$ ), was assayed for $\mathrm{HF}$ by RIA and for albumin and transferrin by radial immunodiffusion (15). Preliminary experiments showed that rat HF added to the fluorocarbon suspension was completely recovered in the supernatant and that the presence of the supernatant or cycloheximide in the assay mixture did not interfere with the RIA. Assay of HF standards gave identical results in the presence or absence of the fluorocarbon supernatant. The rates of $\mathrm{HF}$, albumin, and transferrin production and release, expressed as micrograms per hour per $100 \mathrm{~g}$ body wt, were calculated from the rate of increase in the size of the respective cumulative pools, which was obtained by multiplying the perfusate specific protein concentration by the supernatant volume, with allowance made for previous sampling.

Effect of cycloheximide upon production and release of $H F$. In four experiments, cycloheximide was added to the perfusate after $1 \mathrm{~h}$ to give a final concentration of $18 \mu \mathrm{M}$. This concentration of cycloheximide has previously been shown to inhibit albumin and plasminogen synthesis and release in the isolated perfused rat liver (16).

Incorporation of $\left[{ }^{14} \mathrm{C}\right]$ lysine into $\mathrm{HF}$. In five experiments, $50 \mu \mathrm{Ci}$ of $\mathrm{L}-\left[{ }^{14} \mathrm{C}(\mathrm{U})\right]$ lysine $(>300 \mathrm{mCi} / \mathrm{mmol}$, New England Nuclear, Boston, MA) was added to the reservoir at the start of the perfusion. After $5 \mathrm{~h}$ of perfusion, $\sim 40 \mathrm{ml}$ of perfusate supernatant containing free and incorporated $\left[{ }^{14} \mathrm{C}\right]$ lysine was exhaustively dialyzed against $1 \mathrm{mM}$ nonradioactive lysine in barbital-saline buffer $(0.025 \mathrm{M}$ sodium barbital, $0.125 \mathrm{M}$ sodium chloride, $\mathrm{pH} 7.4$ ). $1 \mathrm{ml}$ of human HF-deficient plasma was added, as a source of carrier proteins, to $10 \mathrm{ml}$ of dialyzed perfusate and the $0-60 \% \mathrm{am}$ monium sulfate fraction was precipitated. The precipitate was dissolved in barbital-saline buffer, dialyzed against the same buffer, and divided in two aliquots. One aliquot was incubated with $0.025 \mathrm{ml}$ of rabbit anti-rat $\mathrm{HF}$ IgG $(17.5 \mathrm{mg} /$ $\mathrm{ml}$ ) for $1 \mathrm{~h}$ at $37^{\circ} \mathrm{C}$ and then overnight at $4^{\circ} \mathrm{C}$. The other aliquot was incubated with normal rabbit $\operatorname{IgG}(17.0 \mathrm{mg} / \mathrm{ml})$ in a similar manner. Goat anti-rabbit IgG serum, $0.1 \mathrm{ml}$ (Antibodies Inc., Paris, CA) was then added to each tube and the mixtures were incubated overnight at $4^{\circ} \mathrm{C}$. The resulting immunoprecipitates were centrifuged and washed three times with ice-cold saline. The washed immunoprecipitates were dissolved in $0.3 \mathrm{ml}$ of hyamine hydroxide (New England Nuclear) and counted in a liquid scintillation spectrometer after the addition of Aquasol scintillator (New England Nuclear). The results were expressed as a percentage of the radioactivity in immunoprecipitates relative to that contained in the initial ammonium sulfate-precipitated protein fraction. 


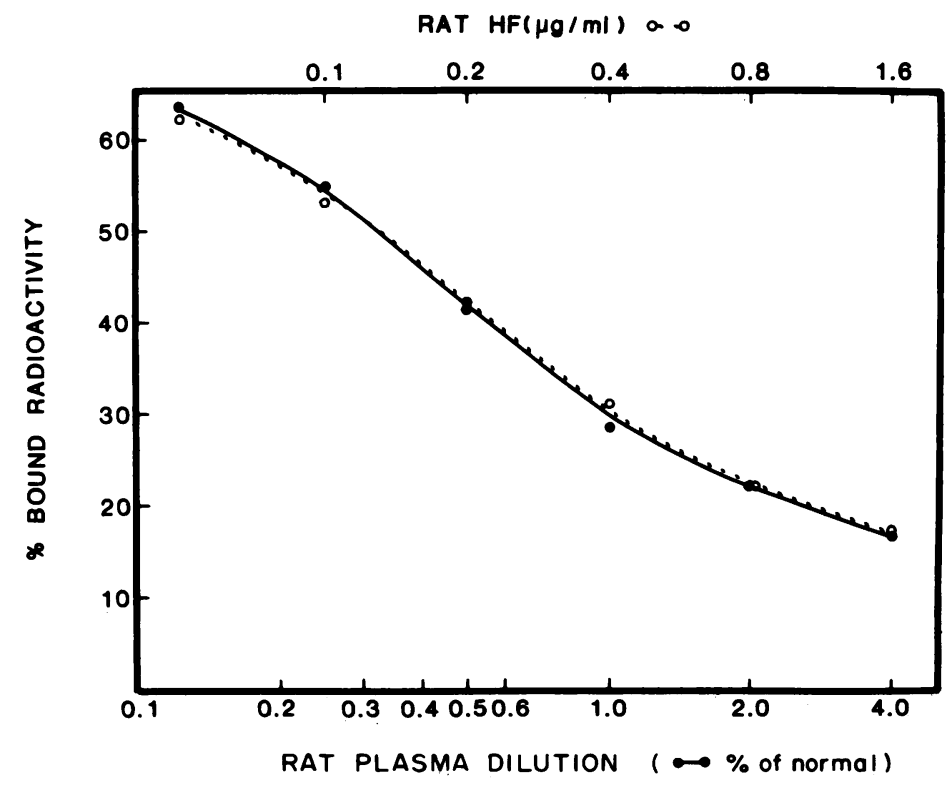

FIGURE 4 RIA of rat HF. Ordinate, percentage of bound radioactivity relative to the total radioactivity added; abscissa, percentage of pooled normal rat plasma (bottom) or micrograms rat $\mathrm{HF}$ per milliter (top).

Measurement of in vivo catabolic rate of $\mathrm{HF}$. Rat $\mathrm{HF}$ $(63 \mu \mathrm{g})$ purified as described above was labeled with ${ }^{125} \mathrm{I}$ by the chloramine-T method (17), at a molar ratio of iodine to protein of no $>0.33$. The final dialyzed ${ }^{125}$ I-rat $\mathrm{HF}$ was $>99 \%$ precipitable with $5 \%$ (wt/vol) trichloroacetic acid (TCA) and had a specific radioactivity of $1.46 \times 10^{6} \mathrm{cpm} / \mu \mathrm{g}$ protein. Four rats were injected with $3.75 \mu \mathrm{g}$ of ${ }^{125} \mathrm{I}-\mathrm{HF}$ via the tail vein. Blood samples $(\sim 150 \mu \mathrm{l})$ were taken into heparinized capillary tubes at intervals for $\sim 120 \mathrm{~h}$. Plasma samples were obtained after centrifugation, and 50 - $\mu$ l aliquots were counted in a gamma spectrometer. Samples of plasma at $10 \mathrm{~min}$ after injection were subjected to SDS-PAGE. This confirmed that the radioactivity was confined to the $80,000-\mathrm{mol}$ wt band. Sequential plasma counts were expressed as a percentage of the value obtained $10 \mathrm{~min}$ after injection. Fractional rates of degradation were calculated by linear regression of the terminal exponential of the plasma decay curves. Absolute rates of degradation were calculated from the product of this value and the mean plasma $\mathrm{HF}$ concentration of $\mathbf{4 0 . 0}$ $\mu \mathrm{g} / \mathrm{ml}$ and a plasma volume of $3.8 \mathrm{ml} / 100 \mathrm{~g}$ body wt (18).

\section{RESULTS}

Appearance of $H F$ in the perfusate. The amount of HF present in the perfusate increased progressively during $5 \mathrm{~h}$ of perfusion (Fig. 5). The HF titers measured in the perfusate in four separate experiments were $10.0 \pm 1.0 \mu \mathrm{g} / 100 \mathrm{~g}$ body wt at $60 \mathrm{~min}, 13.7 \pm 1.4$ $\mu \mathrm{g}$ at $120 \mathrm{~min}, 17.3 \pm 1.7 \mu \mathrm{g}$ at $180 \mathrm{~min}, 21.3 \pm 3.0 \mu \mathrm{g}$ at $240 \mathrm{~min}$, and $23.9 \pm 4.2 \mu \mathrm{g}$ at $300 \mathrm{~min}$ (mean $\pm \mathrm{SEM}$ ). The mean synthetic rate of $\mathrm{HF}$, calculated from the total increase in the perfusate pool between 60 and $300 \mathrm{~min}$ was $3.5 \mu \mathrm{g} / \mathrm{h}$ per $100 \mathrm{~g}$ body wt. From these data it was apparent that after an initial rapid ap- pearance of protein during the first $60 \mathrm{~min}$ there was a continued linear appearance of $\mathrm{HF}$ at a somewhat lower rate for the remaining $\mathbf{2 4 0}$ min of perfusion.

Effect of cycloheximide upon the accumulation of $H F$ in the perfusate. In four perfusion experiments, $18 \mu \mathrm{M}$ cycloheximide was added to the perfusate after the 60-min samples were taken (as indicated by the arrow in Fig. 5). In these experiments the HF titer at $60 \mathrm{~min}$ was $7.8 \pm 1.1 \mu \mathrm{g} / 100 \mathrm{~g}$ body wt (mean $\pm \mathrm{SEM}$ ) and was not significantly different from that in the control experiments $(P>0.05)$. The amount of $\mathrm{HF}$ in

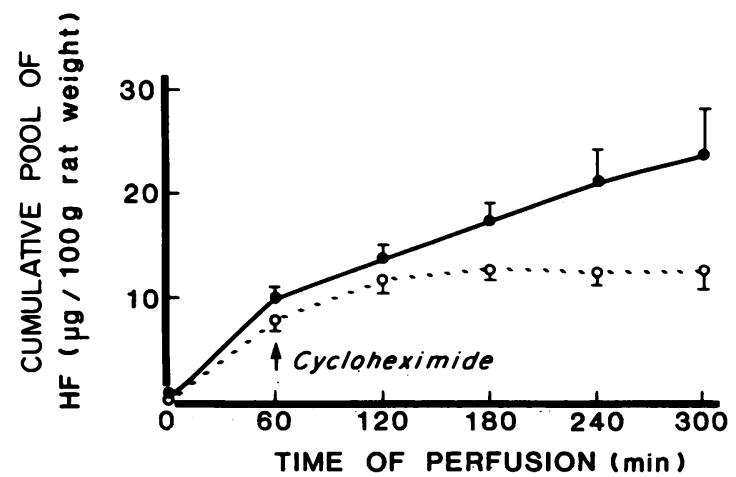

Figure 5 Time course of the appearance of rat $\mathrm{HF}$ in the perfusate of rat liver in the presence and absence of cycloheximide (added 60 min after the start of the perfusion). Bars represent mean \pm SEM $(n=5)$. Control perfusion (-); cycloheximide perfusion $\left(\mathrm{O}_{---O}\right.$ ). 
the perfusate, however, did not increase after $120 \mathrm{~min}$ in the cycloheximide-treated group and there was a statistically significant difference between the control and the cyclohexmide-treated groups at 180,240, and $300 \mathrm{~min}(P<0.025)$. These data indicate that cycloheximide effectively blocked the appearance of $\mathrm{HF}$ in the perfusate, and confirmed that the increase in titer of $\mathrm{HF}$ under normal conditions represents de novo synthesis and not predominant release of preformed protein.

Similar cumulative plots of appearance of protein were demonstrated for both albumin and transferrin (Fig. 6). The synthetic rates derived by linear regression of the cumulative appearance curves for all three proteins were $2,012 \pm 280 \mu \mathrm{g} / \mathrm{h}$ per $100 \mathrm{~g}$ body wt (albumin), $263 \pm 23 \mu \mathrm{g} / \mathrm{h}$ per $100 \mathrm{~g}$ (transferrin), and $3.5 \pm 1.3 \mu \mathrm{g} / \mathrm{h}$ per $100 \mathrm{~g}(\mathrm{HF})$. Therefore, compared in this way, the synthetic rate of $\mathrm{HF}$ was $\sim 0.2 \%$ of that of albumin and $1.4 \%$ of that of transferrin.

Properties of HF released by isolated perfused livers. When an aliquot of 300 -min perfusate was filtered through a column of Sephadex G 150, HF clotpromoting activity and immunoreactive $\mathrm{HF}$ eluted at the same place and had an apparent molecular weight of $\sim 100,000$. This experiment suggests that HF released by liver is functional and that it is approximately the same size as plasma HF (3). When serial dilutions of a similar aliquot of perfusate were tested by RIA, the slope of the displacement curve was similar to that of plasma HF, suggesting that they have similar immunological properties (data not shown).

Incorporation of $\left[{ }^{14} \mathrm{C}\right]$ lysine into $\mathrm{HF}$. Perfusate at $300 \mathrm{~min}$ from five labeling experiments were immunoprecipitated by the sequential addition of either rabbit anti-rat HF IgG or normal rabbit IgG and goat anti-rabbit IgG serum. There was significantly higher

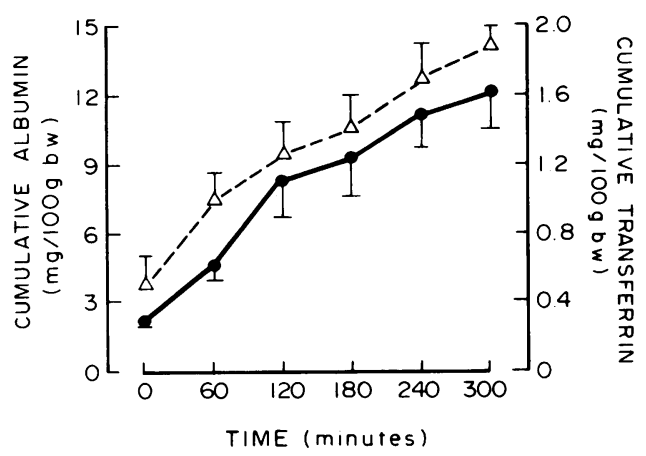

Figure 6 Time course of appearance of rat albumin $(-0)$ and transferrin $(\Delta---\Delta)$. Rates of synthesis calculated by linear regression of the cumulative perfusate pools between 60 and $300 \mathrm{~min}$ were $2.01 \pm 0.28 \mathrm{mg} / \mathrm{h}$ per $100 \mathrm{~g}$ and $0.26 \pm 0.02 \mathrm{mg} / \mathrm{h}$ per $100 \mathrm{~g}$ (mean $\pm \mathrm{SEM}, n=5)$, respectively.
TABLE III

Immunoprecipitation of $\left[{ }^{14} \mathrm{C}\right]$ Lysine-labeled Proteins

\begin{tabular}{|c|c|}
\hline \multicolumn{2}{|c|}{ Percent relative radioactivity ${ }^{\bullet}$ in immunoprecipitates } \\
\hline $\begin{array}{l}\text { Rabbit anti-HF IgG } \\
+ \text { Goat anti-rabbit IgG }\end{array}$ & $\begin{array}{c}\text { Rabbit normal IgG } \\
+ \text { Goat anti-rabbit IgG }\end{array}$ \\
\hline $4.1 \pm 1.0$ & $1.8 \pm 0.4$ \\
\hline \multicolumn{2}{|c|}{$P<0.025$} \\
\hline
\end{tabular}

Data represent mean $\pm \mathrm{SEM} ; n=5$.

- Relative radioactivity is expressed as a percentage of the initial counts per minute in equal aliquots of $0-60 \%$ ammonium sulfate fraction prepared from $10 \mathrm{ml}$ of the 300 -min perfusate supernatant.

${ }^{14} \mathrm{C}$-radioactivity in the specific immunoprecipitates $(4.1 \pm 1.0 \%$, mean \pm SEM) than in the control immunoprecipitates $(1.8 \pm 0.4 \%, P<0.025)$ (Table III). Furthermore, the addition of cycloheximide virtually abolished the incorporation of ${ }^{14} \mathrm{C}$-radioactivity into both specific and control immunoprecipitates.

Absolute catabolic rate of $H F$. The plasma decay curve for the mean catabolic data is shown in Fig. 7. The two exponentials yielded plasma half-lives of 1.4 and $27.0 \mathrm{~h}$, respectively. Since it was apparent that plasma $\mathrm{HF}$ radioactivity had fallen to $\sim 14.5 \%$ of the 10-min value after $\sim 4 \mathrm{~h}$, it was difficult to explain the initial rapid decay on the basis solely of distribution kinetics. It seems likely that other nonidentified routes of loss, including rapid degradation of some HF denatured in the purification process, were responsible for early disappearance. Therefore, the terminal slower exponential was used to calculate and approximate fractional catabolic rate, on the assumption that this represented the degradation of residual native $\mathrm{HF}$. The mean rate constant of this exponential was 0.026 / $h$. The mean absolute catabolic rate calculated from this on the basis of a plasma volume of $3.8 \mathrm{ml} / 100 \mathrm{~g}$ body wt (18) was $4.0 \mu \mathrm{g} / \mathrm{h}$ per $100 \mathrm{~g}$.

\section{DISCUSSION}

The present study was designed to determine the role of the liver in the synthesis of HF by a method that avoids the nonspecificity of functional assay techniques. As such, it confirms and extends the observations of Owen and Bowie $(19,20)$ that the prolonged clotting time of human HF-deficient plasma can be corrected by the addition of perfusate from isolated rat liver. However, since the liver produces many clotting factors (19), such a functional assay may be affected by the presence of other activated procoagulants released by the liver. In contrast, the present studies evaluated the presence of newly synthesized $\mathrm{HF}$, quantified its rate of synthesis by a RIA, and correlated 


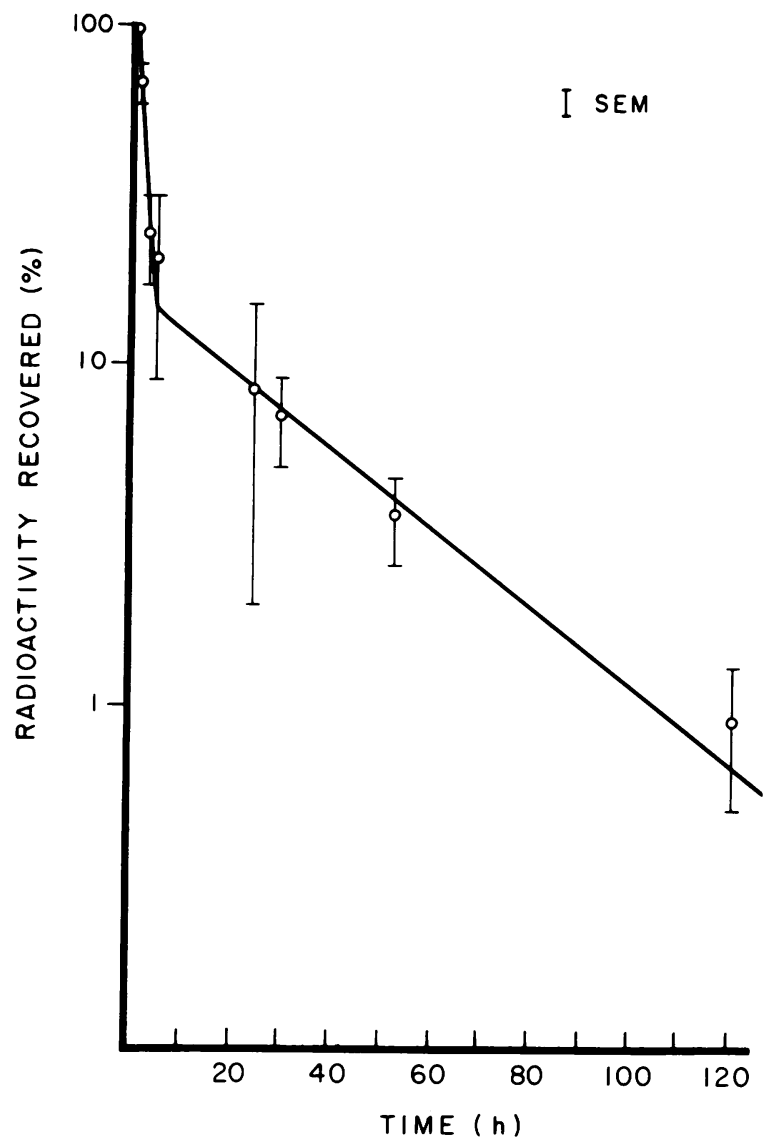

Figure 7 Plasma decay curve of ${ }^{125} \mathrm{I}-\mathrm{HF}$ in the rat. Semilogarithmic plot of percentage of the 10 -min plasma radioactivity (ordinate) is shown at timed intervals (abscissa) in plasma samples of rats injected intravenously with ${ }^{125} \mathrm{I}-\mathrm{HF}$. Bars represent the mean $\pm \mathrm{SEM}, n=4$. The fractional rate of degradation was calculated by linear regression of the terminal exponential of the plasma decay curve (mean rate constant $0.026 / \mathrm{h}, n=5$ ).

such assayable protein with functional activity based upon HF clot-promoting activity.

The validity of our data is intrinsically dependent upon the specificity of the rabbit anti-rat HF serum and RIA technique used. The rat HF used for immunization and for the RIA was judged to be a single homogeneous protein on disc gel electrophoresis, SDSPAGE, and immunodiffusion studies. Amino acid analysis of this preparation was very similar to that of human HF. Furthermore, the anti-rat HF serum raised in rabbits showed a single precipitin line of complete identity with both purified rat $\mathrm{HF}$ and whole rat plasma. Similarly, the monospecificity of this source of antibodies was confirmed by demonstrating that the slopes of the displacement curves for both rat plasma and purified $\mathrm{HF}$ were identical.

The liver perfusion system used a chemically defined artificial Krebs-Ringer bicarbonate perfusate in which $\mathrm{O}_{2}$ transport and delivery was the property of a perfluorocarbon, and oncotic pressure was exerted by hydroxyethyl starch. Thus, the possibility that HF is generated by contaminating blood cells $(21)$ is unlikely. A similar preparation has been shown to main-

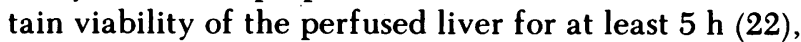
and previous studies in this laboratory have demonstrated that the liver in this system synthesizes plasminogen at physiologic rates (16). Furthermore, similar rates of production of albumin were observed in the present study, as were found in an earlier study that used a more physiological perfusate of plasma and erythrocytes (23). In addition, it is apparent that although the initial rate of appearance of $\mathrm{HF}$ in the perfusate is rapid and may be partially accounted for by release of preformed protein, the linear appearance of HF over the subsequent 240 min represents de novo synthesis of protein. This was confirmed by the efficacy of cycloheximide, an inhibitor of protein synthesis, in almost totally abolishing the appearance of $\mathrm{HF}$ within $60 \mathrm{~min}$ of administration.

Finally, an attempt was made to use the incorporation of $\left[{ }^{14} \mathrm{C}\right]$ lysine into $\mathrm{HF}$ as qualitative evidence for de novo synthesis. In these experiments the entire 300-min perfusate was harvested for double-antibody immunoprecipitation of labeled HF. To allow for nonspecific coprecipitation of other labeled proteins of liver origin present in the ammonium sulfate fraction, a control precipitation was carried out by adding normal rabbit IgG to an equal aliquot followed by goat anti-rabbit IgG. The percent radioactivity precipitated by the specific anti-HF IgG was significantly higher in all five experiments. In other words, the difference in radioactivity incorporated in these two groups of immunoprecipitates represents $\left[{ }^{14} \mathrm{C}\right]$ lysine specifically incorporated into HF. Furthermore, this specific incorporation was also inhibited by cycloheximide.

The hepatic synthetic rate of $\mathrm{HF}$ of $3.5 \mu \mathrm{g} / \mathrm{h}$ per $100 \mathrm{~g}$ body wt calculated from the rate of increase in the cumulative pool of $\mathrm{HF}$ in the isolated perfused rat liver is in close agreement with the estimated absolute rate of catabolism measured in vivo of $4.0 \mu \mathrm{g} / \mathrm{h}$ per $100 \mathrm{~g}$. Although the latter calculation is based upon the slowest component of the plasma half-life; it has been argued that such a method can be expected to yield very similar results to that obtained from measurements of whole body radioactivity (24). The close agreement between this calculated rate of degradation and the rate of synthesis observed in the perfusion system leads us to conclude that the liver is the principal site of HF synthesis and secretion in the rat.

\section{ACKNOWLEDGMENTS}

We would like to thank Dr. O. D. Ratnoff for support and encouragement, and Ms. Susan Gifford and Thea Palmer for invaluable technical assistance. 
This work was supported, in part by grants HL 01661 and RR-05410-16 from the National Institutes of Health, U.S. Public Health Service, and by grants from the American Heart Association and its Northeast Ohio Affiliate.

\section{REFERENCES}

1. Saito, H., S. M. Hamilton, A. Angel, L. Louis, and A. S. Tavill. 1980. Production and release of Hageman factor (HF, Factor XII) by the isolated perfused rat liver. Clin. Res. 28:770a. (Abstr.)

2. Ratnoff, O. D., and H. Saito. 1979. Surface-mediated reactions. Curr. Top. Hematol. 2:1-57.

3. Saito, H., O. D. Ratnoff, and J. Pensky. 1976. Radioimmunoassay of human Hageman factor (factor XII). J. Lab. Clin. Med. 88:506-514.

4. Veltkamp, J. J., E. A. Loeliger, and H. C. Hemker. 1965. The biological half-time of Hageman factor. Thromb. Diath. Haemorrh. 13:1-7.

5. Proctor, R. R., and S. I. Rapaport. 1961. The partial thromboplastin time with kaolin. Am. J. Clin. Pathol. 36:212-219.

6. Saito, H., O. D. Ratnoff, R. Waldmann, and J. P. Abraham. 1975. Fitzgerald trait: deficiency of a hitherto unrecognized agent, Fitzgerald factor, participating in surface-mediated reactions of clotting, fibrinolysis, generation of kinins, and the property of diluted plasma enhancing vascular permeability (PF/Dil). J. Clin. Invest. 55:1082-1089.

7. McMillin, C. R., H. Saito, O. D. Ratnoff, and A. G. Walton. 1974. The secondary structure of human Hagemán factor (Factor XII) and its alteration by activating agents. J. Clin. Invest. 54:1312-1322.

8. Davies, B. J. 1964. Disc electrophoresis II. Method and application to human serum protein. Ann. NY Acad. Sci. 121:404-427.

9. Weber, K., and M. Osborn. 1969. The reliability of molecular weight determination by dodecyl sulfate polyacrylamide gel electrophoresis. J. Biol. Chem. 244:44064412.

10. Fairbanks G., T. L. Steck, and D. F. H. Wallach. 1971. Electrophoretic analysis of the major polypeptides of the human erythrocyte membrane. Biochemistry. 10:26062617.
11. Righetti, P. G., and J. W. Drysdale. 1971. Isoelectric focusing in polyacrylamide gels. Biochim. Biophys. Acta. 236:17-25.

12. Griffin, J. H., and C. G. Cochrane. 1976. Human factor XII (Hàgeman factor). Methods Enzymol. 45:56-65.

13. Fujikawa, K., K. A. Walsh, and E. W. Davie. 1977. Isolation and characterization of bovine Factor XII (Hageman factor). Biochemistry. 16:2270-2275.

14. Steinbuch, M., and R. Audran. 1969. The isolation of IgG from mammalian sera with the aid of caprylic acid. Arch. Biochem. Biophys. 134:279-284.

15. Mancini, G., A. O. Carbonara, and J. F. Heremans. 1965. Immunochemical quantitation of antigens by single radial immunodiffusion. Immunochemistry. 2:235-254.

16. Saito, H., S. M. Hamilton, A. S. Tavill, L. Louis, and O. D. Ratnoff. 1980. Production and release of plasminogen by the isolated perfused rat liver. Proc. Natl. Acad. Sci. USA. 77:6837-6840.

17. McConahey, P. J., and F. J. Dixon. 1966. A method of trace iodination of proteins for immunologic studies. Int Arch. Allergy Appl. Immunol. 29:185-189.

18. Gardiner, M. E., and E. H. Morgan. 1974. Transferrin and iron uptake by the liver in the rat. Aust. J. Exp. Biol. Med. Sci. 52:723-736.

19. Owen, C. A., Jr., and E. J. W. Bowie. 1977. Generation of coagulation Factors V, XI, and XII by the isolated rat liver. Haemostasis. 6:205-212.

20. Owen, C. A., and E. J. W. Bowie. 1981. Generation of plasmatic coagulation factors by the isolated rat liver perfused with completely synthetic blood substrate. Thromb. Res. 22:259-66.

21. Owen, C. A., Jr., and E. J. W. Bowie. 1975. A clotting artifact in isolated rat liver perfusions. Thromb. Res. 7:765-775

22. Nováková, V., G. Birke, L.-O. Plantin, and A. Wretlind. 1976. A perfluorochemical oxygen carrier (Fluosol-43) in a synthetic medium used for perfusion of isolated rat liver. Acta Physiol. Scand. 98:356-365.

23. Morton, A. G., and A. S. Tavill. 1977. The role of iron in the regulation of hepatic transferrin synthesis. $\mathrm{Br} . \mathrm{J}$. Haematol. 36:383-394.

24. Regoeczi, E., and M. W. C. Hatton. 1980. Transferrin catabolism in mammalian species of different body sizes. Am. J. Physiol. 238:306-319. 